\title{
Reduction of duplicate scientific Journal titles in Greek libraries: an economic assessment
}

\author{
Filippos Tsimpoglou \\ University of Cyprus, Nicosia, Cyprus \\ 75 Kallipoleos Street, PO Box 20537,1678 Nicosia, Cyprus. \\ e-mail: ftsimp@ucy.ac.cy, URL: http://www.ucy.ac.cy/ ftsimp
}

\begin{abstract}
.
In 1983, the National Hellenic Documentation Centre started the development of the Union Catalogue of Periodicals in the Hellenic Scientific and Technological Libraries. The union catalogue was developed in a database form. Today (January 2000), the union catalogue includes 206 Hellenic scientific, technological and medical libraries, two of which are located in Cyprus. These libraries belong to a wide range of organisational and institutional types, such as universities, hospitals, research institutions, private companies and commercial banks, covering all scientific and technological fields. The total national collection of serials amounts to 22,790 unique titles, which correspond to 57,790 subscriptions. The overlapping coefficient is at 2.53 (= subscriptions per unique journal title). The annual cost comes to 25,195 million Euros $(1$ Euro $=328$ drachmas). A macroeconomic approach is attempted, to investigate the upper and lower levels of savings that could be realised by reduction of over-lapping subscriptions. While library budgets have been continuously cut during recent years, under certain conditions, a reasonable and coordinated reconstruction of the individual libraries' collections could save every year $20 \%-50 \%$ of the total subscription cost and therefore expand the national collection by the same percentage. Two important steps towards these directions were the development of the Hellenic Interlibrary Loan Network and the Hellenic Academic Library Link.
\end{abstract}

\section{Introduction}

Living in the dawn of the digital era, developing digital libraries, passing from acquisition (of printed journals) to access (to electronic titles) and investigating alternative methods, techniques and charges for better library and information services, it is important to record the current situation and derive conclusions on what libraries can and/or have to do, in order to fulfill their aims. This paper focuses on the cost of printed collections held by the Hellenic scientific libraries and traces the margins they have to expand their services through the reduction of overlapping titles and the reasonable and coordinated reconstruction of their collections.

\section{Background}

The development of the Union Catalogue of Periodicals started in 1983. It was the first online database created by the National Hellenic Documentation Centre (NDC). The NDC, already having online access to more than 800 international databases via its 
connection to more than fourteen commercial host computers, and a group of scientific experts acting as information intermediaries, could ensure to an adequate degree the first link of the information chain: the search and retrieval of bibliographic references.

The Union Catalogue of Periodicals was created to cover the second link, acting as a tool for identification of the original documents in the Hellenic libraries. The first edition of the printed union catalogue was published in 1985. It included 5,000 scientific journal titles, which corresponded to the collection of five libraries of institutions supervised and financed by the Ministry of Research and Technology (the National Hellenic Research Foundation (to which the NDC belongs), National Centre for Physical Research 'Democritus', Pasteur Institute, National Centre for Social Research and the National Centre of Marine Research). Although the catalogue has been available since 1985 as an online database [1], it was mostly known to Hellenic libraries for its printed versions. More than 2,000 copies had been disseminated for each one of the four printed editions to libraries all over the country. The union catalogue is continuously expanded with new libraries and updated by the NDC in collaboration with the scientific and technological libraries of the country [2].

\section{Infrastructure}

The technological infrastructure used was the host computer 'HERMES' of NDC, which was installed in 1993. The whole system is virtually identical to the host computers used by ECHO (European Commission Host Organisation) in Luxembourg and DIMDI (Deutsche Institut für Medizinisch Dokumentation und Information) in Germany. The system comprises a mainframe Siemens/Nixdorff (SNI), operation system BS2000 and the database management system (DBMS) GRIPS. The query language was common command language (CCL). A graphical user interface (GUI) based on client-server architecture was also available. Online document ordering functions were provided by the system.

\section{Union catalogue of periodicals (SERI)}

As the union catalogue of periodicals, SERI includes the collections of almost all of the scientific and research libraries in Greece, data and conclusions derived from the union catalogue database can safely be considered to depict the status of the total national collection of scientific journals in Greece.

SERI [3] includes 206 Hellenic libraries (two of them located in Cyprus). The total collection includes 22,790 titles, corresponding to 57,790 subscriptions. Subscriptions are more than two-and-a-half times the titles, raising the overlapping coefficient to 2.53 (= subscriptions per title).

Table 1 presents the evolution of the Union Catalogue of Periodicals. The first four dates $(1985,1987,1989,1992)$ correspond to the printed editions, while the others present the status of the online database during subsequent years.

In Table 2, the distribution of libraries according to institutional and organisational status 
is presented. Half of the libraries $(49.75 \%)$ belong to universities, covering half of the journal subscriptions (49.57\%). The average size of a library's subscriptions is 287 journal titles, varying between the different categories. Commercial banks and research institution libraries have a higher average size in terms of subscriptions (622). University libraries appear to have a lower average of subscriptions (286), as both central and departmental libraries are included in this category.

In Table 3, the distribution of 201 libraries of SERI is presented in categories of size of their collections. The journal collections of $114(=4+36+74)$ libraries, which represent $56.7 \%$ of the total, do not have more than 200 titles; $83.1 \%$ of the total number of libraries run collections which have less than 500 journal titles. Only nine libraries include in their collections 1,001-2,500 journal titles. Corresponding sizes concerning only current titles are even smaller, after the budget cuts of last year.

Table 1.

Evolution of the Union Catalogue of Periodicals in scientific and technological libraries in Greece

\begin{tabular}{|r|r|r|c|c|}
\hline Years & $\begin{array}{c}\text { Number of } \\
\text { Libraries }\end{array}$ & $\begin{array}{c}\text { Number of } \\
\text { Journal } \\
\text { Titles }\end{array}$ & $\begin{array}{c}\text { Number of } \\
\text { subscriptions }\end{array}$ & $\begin{array}{c}\text { Overlapping } \\
\text { coefficient }\end{array}$ \\
\hline 1985 Edition 1 & 5 & 5.000 & N/A & N/A \\
\hline 1987 Edition 2 & 15 & 10.000 & N/A & N/A \\
\hline 1989 Edition 3 & 45 & 15.000 & N/A & N/A \\
\hline 1992 Edition 4 & 104 & 19.000 & N/A & N/A \\
\hline Nov 1994 & 133 & 20.400 & 48.057 & 2,36 \\
\hline Nov 1995 & 167 & 20.614 & 49.800 & 2,42 \\
\hline Sep 1996 & 190 & 21.100 & 53.224 & 2,52 \\
\hline Sep 1997 & 206 & 22.790 & 57.790 & 2,53 \\
\hline
\end{tabular}

Table 2.

Distribution of libraries included in the "Union Catalogue of Periodicals", according to their institutional and organisational status.

\begin{tabular}{|l|r|r|r|r|r|r|r|r|}
\hline $\begin{array}{l}\text { Institutional or } \\
\text { organisational } \\
\text { categories }\end{array}$ & $\begin{array}{c}\text { Number } \\
\text { of } \\
\text { Librarie } \\
\text { s }\end{array}$ & $\begin{array}{c}\text { Percentage } \\
\text { of } \\
\text { Libraries } \\
\text { number }\end{array}$ & $\begin{array}{c}\text { Number } \\
\text { of } \\
\text { Subscriptions }\end{array}$ & $\begin{array}{c}\text { Percentage } \\
\text { of } \\
\text { Subscriptions }\end{array}$ & $\begin{array}{c}\text { Average of } \\
\text { subscriptions } \\
\text { per library }\end{array}$ & min & max & $\begin{array}{c}\text { Standard } \\
\text { deviation }\end{array}$ \\
\hline $\begin{array}{l}\text { Higher Education } \\
\text { Libraries }\end{array}$ & 100 & $49,75 \%$ & 28.620 & $49,57 \%$ & 286 & 8 & 1568 & 332,9 \\
\hline Hospital Libraries & 33 & $16,42 \%$ & 7.201 & $12,47 \%$ & 218 & 51 & 820 & 170,5 \\
\hline Special Libraries & 32 & $15,92 \%$ & 7.005 & $12,13 \%$ & 219 & 20 & 1374 & 280,0 \\
\hline Research libraries & 18 & $8,96 \%$ & 11.199 & $19,40 \%$ & 622 & 18 & 2509 & 755,3 \\
\hline $\begin{array}{l}\text { Technological } \\
\text { Education }\end{array}$ & 8 & $3,98 \%$ & 956 & $1,66 \%$ & 120 & 24 & 261 & 93,5 \\
\hline $\begin{array}{l}\text { Private } \\
\text { Educational } \\
\text { Institutes }\end{array}$ & 7 & $3,48 \%$ & 622 & $1,08 \%$ & 89 & & & 186 \\
\hline Commercial Banks & 3 & $1,49 \%$ & 2.136 & $3,70 \%$ & 712 & 578 & 833 & 128,0 \\
\hline Totals & $\mathbf{2 0 1}$ & $\mathbf{1 0 0 , 0 0 \%}$ & $\mathbf{5 7 . 7 3 9}$ & $\mathbf{1 0 0 , 0 0 \%}$ & $\mathbf{2 8 7}$ & $\mathbf{8}$ & $\mathbf{2 5 0 9}$ & $\mathbf{3 7 1 , 1}$ \\
\hline
\end{tabular}


Table 3.

Distribution of libraries in categories of size of the collection

\begin{tabular}{|c|c|c|c|}
\hline $\begin{array}{c}\text { Size of the collection in } \\
\text { journal titles }\end{array}$ & $\begin{array}{c}\text { Number of } \\
\text { libraries }\end{array}$ & Percentage & $\begin{array}{c}\text { Cumulative } \\
\text { percentage }\end{array}$ \\
\hline $0-10$ & 4 & $2,0 \%$ & $2,0 \%$ \\
\hline $11-50$ & 36 & $17,9 \%$ & $19,9 \%$ \\
\hline $51-200$ & 74 & $36,8 \%$ & $56,7 \%$ \\
\hline $201-500$ & 53 & $26,4 \%$ & $83,1 \%$ \\
\hline $501-1000$ & 25 & $12,4 \%$ & $95,5 \%$ \\
\hline $1001-1500$ & 5 & $2,5 \%$ & $98,0 \%$ \\
\hline $1501-2500$ & 4 & $2,0 \%$ & $100,0 \%$ \\
\hline Total & $\mathbf{2 0 1}$ & $\mathbf{1 0 0 \%}$ & \\
\hline
\end{tabular}

In addition to the Union Catalogue of Periodicals, another special union catalogue, consisting of 2,570 journal titles from libraries participating in the ARGOS (Archaeological Greek Online System) project, has also been developed by the NDC, but is not yet included in union catalogue of periodicals, SERI. All fifteen libraries of foreign archaeological schools established and operating in Greece, as well as the two libraries of the Humanistic Institutes of the National Hellenic Research Foundation (NHRF), are participating in the development of the ARGOS union catalogue of periodicals. The incorporation of these collections in SERI is planned for the end of 2000. However, the union catalogue of archaeological libraries is already available as ARGP [4], a distinct online database of HERMES, the host computer of the NDC. 


\section{Economic assessment of benefits resulting the overlapping reduction}

In the following paragraphs, a macro approach is attempted in order to investigate the upper and lower levels of the economic benefits resulting from the reduction of overlapping journal titles. The further objective of such an assessment is to determine the boundaries of expansion of the national collection of journal titles through the reconstruction of local collections, keeping the total budget of libraries at levels similar to the current ones. The tools for such an operation are HILLnet (the Hellenic Interlibrary Loan Network, which is based on the Union Catalogue of Periodicals in the Hellenic Scientific and Technological Libraries) and HEAL-Link (the Hellenic Academic Library Link).

The analysis is based on Table 4. The primary data are those of columns A and D, which were available to every user of the SERI database on HERMES via the command $\mathrm{D} \mathrm{NL}=\$$. The result of this command was the display of the number of journal titles (column A) that belong to the collection of 1, 2, 3, 4, etc, libraries (column D).

Column A of Table 4 presents the number of titles, the subscriptions of which are duplicated in a number of libraries, as shown in column D (number of overlapping subscriptions). In the first row of data, 12,545 journal titles appear to be unique, i.e. they are to be found in only one library (not all of them in the same). In the second row of data, 3,819 titles are duplicated in the collections of two libraries. The subscription to 2,005 titles is paid three times, i.e. by three different libraries for each title (third row of data). In a similar way, the subscription to 1,212 titles is paid four times, for 844 titles five times and so on, while there are three titles repeated in 30 different libraries, two in 44, and one repeated in 54 libraries (!).

The last row of columns $\mathrm{A}$ and $\mathrm{E}$ inform us that 57,790 subscriptions correspond to 22,790 journal titles and that the 'overlapping coefficient' rises to 2.53 , i.e. for each one of the journal titles of the national collection, there are 2.53 subscriptions or every title is bought for 2.53 times its cost in the frame of the current composition of the national collection.

Column B presents the percentage of the number of titles of every row in comparison to the total of 22,790 journal titles of the national collection. Column $\mathrm{C}$ presents the previous percentage cumulatively: $55.0 \%$ of the titles are not repeated, as they are unique titles of one library (not the same library). In other words, the subscription for $55.0 \%$ of the total number of 22,790 titles, which consist of the total of the national collection, is paid only once all over the country. A question arising is whether the percentage of $55.0 \%$, representing the unique titles of the national collection is 'acceptable' in comparison with the corresponding percentage of other countries. Nevertheless, according to this author's perception, the fact that $16,364(=12,545+$ $3,819)$ titles, which constitute $71.8 \%$ ( $=55.0 \%+16.8 \%)$ of the national collection, are not repeated more than twice is a positive point, taking into account the lack of coordinated planning in the development of individual collections.

Column $\mathrm{E}$ is derived as the product of data of column A multiplied with data of column D. Column E presents the total number of subscriptions for each group of titles appearing in the same row of column A, e.g. in the sixth row, it appears that 627 titles (column A) are repeated six times by different libraries (column D), so the cost 
of 3,762 (= $627 \mathbf{X}$ 6) subscriptions (column E) is paid for obtaining only 627 unique titles.

Column $\mathrm{F}$ is derived as the product of the total number of subscriptions (column $\mathrm{E}$ ) multiplied by the mean subscription cost (MSC). MSC was considered as the corresponding mean cost of the subscriptions paid by the library of the National Hellenic Research Foundation (NHRF), which covers a wide range of scientific fields. The NHRF collection of journals includes 1,400 current journal titles of both low and high annual subscription cost. MSC is estimated at 436 Euros ( $=143,000$ Greek drachmas). The strictly accurate estimation of the analysis requires the knowledge of the annual subscription cost of each one of the 22,790 titles. This procedure needs effort, which is beyond the aims of this paper. Quite reliable and easier to achieve are the cross-checks with the weighted mean subscription cost, derived from each one of the 206 libraries included in the union catalogue. This MSC, used in the analysis below, seems to be impressively comparable to what was reported by the survey of the Total Quality Unit of Academic Libraries, University of Ioannina: data collected concerning the number of journal subscriptions and the expenses accrued during 1998 by fourteen universities and technological and educational institutions raises the MSC of their 17,987 journal subscriptions to between 404 and 418 Euros [5].

However, amounts presented in column $\mathrm{F}$ are somewhat overestimated, because two types of titles are also included:

(1) a certain number of titles ceased;

(2) a number of titles were received at no charge.

The last row of column F presents the total annual cost of the national collection, which totals to an amount of 25,195,030 Euros.

Two extreme hypotheses follow. The economic results of each one are depicted in columns $\mathrm{G}$ and $\mathrm{H}$ respectively.

Column $\mathrm{G}$ estimates the minimum expected economic benefit resulting if only one subscription is going to be cut for each one of the repeated titles. For example, in the fifth row, if each one of the 844 titles (column A) is to be cut from only one of the five libraries (column D) which pay for it, then the annual economic benefit resulting totals 367,963 Euros (column G). This amount could be available for the acquisition of titles not yet included in the national collection. At the same time, the 844 titles will continue to be still repeated in four (and not any more in five) libraries. Similarly, in the sixth row, ceasing each one of the 627 titles from only one of the six libraries, which pay for it, an amount of 273,357 Euros is saved annually for the acquisition of new titles of equal cost. The total annual minimum expected economic benefit is estimated at 4,466,570 Euros (last row of column G).

Column $\mathrm{H}$ estimates the maximum expected economic benefit resulting if only one subscription is to be kept for each one of the repeated titles. For example, in the fifth row, if, for each one of the 844 titles (column A), the subscriptions from all except one library are to be cut (i.e. four out of five libraries of column D), then the annual economic benefit rises to 1,471,854 Euros (column H). This amount of money could be available for the acquisition of new titles not included in the national collection. Similarly, in the sixth row, cutting each one of the 627 titles from all but one (i.e. $5=$ $6-1)$ libraries, which pay for them, and keeping these titles in only one library out 
of six, an annual saving of 1,366,784 Euros is estimated to be saved for the acquisition of new titles of equal cost. The annual total of maximum expected economic benefit is estimated at the amount of 15,259,146 Euros (last row of column $\mathrm{H})$.

The two hypotheses examined above reflect two extreme cases of a macro approach. The expected economic benefit resulting from the reduction of overlapping titles is estimated to be between the results of the two approaches, i.e. 4.46 and 15.25 million Euros per year. The results of such a macro approach have opened up the possibility for a more detailed approach and coordinated planning for the reconstruction of the individual libraries' collections. The approach from the individual libraries' point of view sets more limitations and restrictions (e.g. keeping in-house a minimum number of titles needed for the operation of the individual library). Nevertheless, at the same time, the degrees of freedom for the national collection are increased, as more than one library can cease or substitute quite a number of duplicated titles. 
Table 4.

Journal titles duplication and corresponding costs

\begin{tabular}{|c|c|c|c|c|c|c|c|}
\hline $\mathbf{A}$ & B & $\mathbf{C}$ & D & $\mathbf{E}$ & $\mathbf{F}$ & $\mathbf{G}$ & $\bar{H}$ \\
\hline & & & & $\mathbf{A} * \mathbf{D}$ & $E * \mathbf{M S C}$ & $\mathbf{A} * \mathbf{M S C}$ & $(\mathbf{E}-\mathrm{A}) * \mathbf{M S C}$ \\
\hline $\begin{array}{c}\text { NUMBER } \\
\text { OF } \\
\text { TITLES }\end{array}$ & $\%$ OF TITLES & $\begin{array}{l}\text { CUMULATIVE } \\
\text { PERCENTAGE }\end{array}$ & $\begin{array}{c}\text { NUMBER OF } \\
\text { OVERLAPPING } \\
\text { SUBSCRIPTIONS }\end{array}$ & $\begin{array}{l}\text { TOTAL NUMBER } \\
\text { OF } \\
\text { SUBSCRIPTIONS }\end{array}$ & $\begin{array}{c}\text { TOTAL } \\
\text { SUBSCRIPTIONS } \\
\text { COST } \\
\text { (in EURO) }\end{array}$ & $\begin{array}{l}\text { MINIMUM } \\
\text { EXPECTED } \\
\text { ECONOMIC } \\
\text { BENEFIT } \\
\text { (in EURO) }\end{array}$ & $\begin{array}{l}\text { MAXIMUM } \\
\text { EXPECTED } \\
\text { ECONOMIC } \\
\text { BENEFIT } \\
\text { (in EURO) }\end{array}$ \\
\hline 12.545 & $55,046 \%$ & $55,046 \%$ & 1 & 12.545 & 5.469 .314 & & \\
\hline 3.819 & $16,757 \%$ & $71,803 \%$ & 2 & 7.638 & 3.329 .982 & 1.664 .991 & 1.664 .991 \\
\hline 2.005 & $8,798 \%$ & $80,601 \%$ & 3 & 6.015 & 2.622 .393 & 874.131 & 1.748 .262 \\
\hline 1.212 & $5,318 \%$ & $85,919 \%$ & 4 & 4.848 & 2.113 .610 & 528.402 & 1.585 .207 \\
\hline 844 & $3,703 \%$ & $89,623 \%$ & 5 & 4.220 & 1.839 .817 & 367.963 & 1.471 .854 \\
\hline 627 & $2,751 \%$ & $92,374 \%$ & 6 & 3.762 & 1.640 .140 & 273.357 & 1.366 .784 \\
\hline 435 & $1,909 \%$ & $94,283 \%$ & 7 & 3.045 & 1.327 .546 & 189.649 & 1.137 .896 \\
\hline 327 & $1,435 \%$ & $95,717 \%$ & 8 & 2.616 & 1.140 .512 & 142.564 & 997.948 \\
\hline 228 & $1,000 \%$ & $96,718 \%$ & 9 & 2.052 & 894.622 & 99.402 & 795.220 \\
\hline 149 & $0,654 \%$ & $97,372 \%$ & 10 & 1.490 & 649.604 & 64.960 & 584.643 \\
\hline 129 & $0,566 \%$ & $97,938 \%$ & 11 & 1.419 & 618.649 & 56.241 & 562.409 \\
\hline 80 & $0,351 \%$ & $98,289 \%$ & 12 & 960 & 418.537 & 34.878 & 383.659 \\
\hline 74 & $0,325 \%$ & $98,613 \%$ & 13 & 962 & 419.409 & 32.262 & 387.146 \\
\hline 71 & $0,312 \%$ & $98,925 \%$ & 14 & 994 & 433.360 & 30.954 & 402.405 \\
\hline 43 & $0,189 \%$ & $99,114 \%$ & 15 & 645 & 281.204 & \begin{tabular}{l|l|}
18.747 \\
\end{tabular} & 262.457 \\
\hline 28 & $0,123 \%$ & $99,237 \%$ & 16 & 448 & 195.317 & \begin{tabular}{l|l|}
12.207 \\
\end{tabular} & 183.110 \\
\hline 25 & $0,110 \%$ & $99,346 \%$ & 17 & 425 & 185.290 & 10.899 & 174.390 \\
\hline 18 & $0,079 \%$ & $99,425 \%$ & 18 & 324 & 141.256 & 7.848 & 133.409 \\
\hline 15 & $0,066 \%$ & $99,491 \%$ & 19 & 285 & 124.253 & 6.540 & 117.713 \\
\hline 16 & $0,070 \%$ & $99,561 \%$ & 20 & 320 & 139.512 & 6.976 & 132.537 \\
\hline 14 & $0,061 \%$ & $99,623 \%$ & 21 & 294 & 128.177 & 6.104 & 122.073 \\
\hline 9 & $0,039 \%$ & $99,662 \%$ & 22 & 198 & 86.323 & 3.924 & 82.399 \\
\hline 9 & $0,039 \%$ & $99,702 \%$ & 23 & 207 & 90.247 & 3.924 & 86.323 \\
\hline 11 & $0,048 \%$ & $99,750 \%$ & 24 & 264 & 115.098 & 4.796 & 110.302 \\
\hline 9 & $0,039 \%$ & $99,789 \%$ & 25 & 225 & 98.095 & 3.924 & 94.171 \\
\hline 6 & $0,026 \%$ & $99,816 \%$ & 26 & 156 & 68.012 & 2.616 & 65.396 \\
\hline 6 & $0,026 \%$ & $99,842 \%$ & 27 & 162 & 70.628 & 2.616 & 68.012 \\
\hline 4 & $0,018 \%$ & $99,860 \%$ & 28 & 112 & 48.829 & 1.744 & 47.085 \\
\hline 5 & $0,022 \%$ & $99,882 \%$ & 29 & 145 & 63.216 & 2.180 & 61.037 \\
\hline 3 & $0,013 \%$ & $99,895 \%$ & 30 & 90 & 39.238 & 1.308 & 37.930 \\
\hline 4 & $0,018 \%$ & $99,912 \%$ & 31 & 124 & 54.061 & 1.744 & 52.317 \\
\hline 3 & $0,013 \%$ & $99,925 \%$ & 32 & 96 & 41.854 & 1.308 & 40.546 \\
\hline 2 & $0,009 \%$ & $99,934 \%$ & 33 & 66 & 28.774 & 872 & 27.902 \\
\hline 3 & $0,013 \%$ & $99,947 \%$ & 34 & 102 & \begin{tabular}{|l|}
44.470 \\
\end{tabular} & 1.308 & 43.162 \\
\hline 1 & $0,004 \%$ & $99,952 \%$ & 35 & 35 & 15.259 & 436 & 14.823 \\
\hline 1 & $0,004 \%$ & $99,956 \%$ & 42 & 42 & 18.311 & 436 & 17.875 \\
\hline 1 & $0,004 \%$ & $99,961 \%$ & 38 & 38 & \begin{tabular}{l|l|}
16.567 \\
\end{tabular} & 436 & 16.131 \\
\hline 1 & $0,004 \%$ & $99,965 \%$ & 39 & 39 & 17.003 & 436 & 16.567 \\
\hline 1 & $0,004 \%$ & $99,969 \%$ & 41 & 41 & 17.875 & 436 & 17.439 \\
\hline 2 & $0,009 \%$ & $99,978 \%$ & 44 & 88 & 38.366 & 872 & 37.494 \\
\hline 2 & $0,009 \%$ & $99,987 \%$ & 48 & 96 & 41.854 & 872 & 40.982 \\
\hline 1 & $0,004 \%$ & $99,991 \%$ & 50 & 50 & 21.799 & 436 & 21.363 \\
\hline 1 & $0,004 \%$ & $99,996 \%$ & 53 & 53 & 23.107 & 436 & 22.671 \\
\hline 1 & $0,004 \%$ & $100,000 \%$ & 54 & 54 & 23.543 & 436 & 23.107 \\
\hline 22.790 & $100,000 \%$ & & & 57.790 & 25.195 .030 & 4.466 .570 & 15.259 .146 \\
\hline \multicolumn{5}{|c|}{$\overline{\text { Percentage on annual cost of national collection }}$} & $100 \%$ & $18 \%$ & $61 \%$ \\
\hline
\end{tabular}

\section{Overlapping coefficient $\mathbf{2 , 5 3 6}$}




\section{Confronting the cost of overlapping reduction}

The reduction of subscriptions that are duplicated on a national level impacts immediately on the quality and the quantity of services previously offered by individual libraries to their patrons. The following questions are raised:

(1) through which mechanisms and arrangements could individual Hellenic libraries offer the same (if not more and better) services to their users, in order to balance the reduction of quality of services occurred by the reduction of overlapping titles?

(2) at what cost can these arrangements ensure an equal or higher level of services offered by individual libraries or, alternatively, how will the end-users not bear the cost, which is raised by the development and operation of these mechanisms?

The answers to these questions were suggested through the development of two mechanisms: HILLnet (the Hellenic Interlibrary Loan Network) and HEAL-Link (the Hellenic Academic Library Link).

\section{HILLnet}

HILLnet [6] is an initiative of the NDC, aimed at the development of an infrastructure, the creation of the appropriate mechanism and the acquisition of know-how for cooperation between libraries. Through HILL-net, the upgrade of services offered by libraries and the optimisation of the continuously decreased budgets of the libraries was attempted. A first service developed by

HILLnet was the online document ordering of journal articles included in the collections of member libraries.

Starting with the participation of six libraries in February 1994, HILLnet was gradually developed during the last few years, currently comprising 119 participating libraries (at January 2000). For the moment, access to HILLnet is permitted only to those Hellenic scientific and technological libraries that are members of the union catalogue of periodicals. Trained staff of the participating libraries carry out online searches to the union catalogue. After identifying the libraries holding the requested journal, they make the orders on behalf of their end-users. Document delivery is carried out via ordinary mail or fax. Transactions between libraries are recorded on the central computer of the NDC. Clearance is carried out once per year by the NDC. End-users are charged for the photocopies and mailing costs involved. More than 75,000 online document orders have been executed via HILLnet during the last six years.

Due to the existence and operation of HILLnet, a percentage of the decrease in quality of services, caused by the cuts in budgets and consequently the cessation of titles during the last years, was recovered. Libraries were pressed anyway to suspend quite a large number of their subscriptions. Even if the systematic and coordinated reduction of duplicated titles was not the case, the contribution of HILLnet is considered of great importance in this area, for two reasons:

(1) a defensible but reasonable attitude to the compulsory cutting of titles was followed. Duplicated titles were of first priority for cutting. This resulted in keeping the national 
collection relatively untouched in terms of unique titles;

(2) even after an individual library has cut one of the duplicated titles, obtaining photocopies of articles of this journal is possible via interlibrary loan within the country from other member libraries of HILLnet that keep the title in their collection.

\section{Heal-Link}

HEAL-Link has been operating since 1999 as a consortium. All 32 higher education institutions of Greece, the Academy of Athens and the National Library of Greece are participating in HEAL-Link. One of the objectives of HEAL-Link is the 'common subscription to electronic resources and information services, as well as licences for remote access to electronic resources and information services, including electronic scientific journals' [7]. The creation of HEAL-Link was originally suggested and described in the Technical Report of the Horizontal Action for Libraries, which was funded by the Second Community Support Framework of the European Union

to Greece. The final specifications, as well as the strategy of creation and organisation, were reviewed and stated in December 1997 in the final report of the Working Group for Journals [8]. In November 1998, HEAL-Link became a member of the International Coalition of Library Consortia (ICOLC) [9]. After more than one year of negotiations, the Steering Group of HEAL-link has reached agreements, signing contracts with the following electronic information services:

(1) Elsevier Science: three-year agreement for access to the full text of more than 1,000 electronic journals;

(2) OCLC: access to about 1,000 electronic journals of 32 publishers via Electronic Collections Online and twelve more OCLC services and databases;

(3) Wilson's OMNI Megafile, with access to 1,100 electronic journals;

(4) Springer-Verlag: one-year agreement for 400 journals available via Link service;

(5) Academic Press: three-year agreement covering 200 journals of IDEAL services;

(6) MCB: three-year agreement for 119 journals of the Emerald Library;

(7) Kluwer: (under negotiations) for 350 electronic journals and 83 more published by Plenum Academic Press.

(8) Agreements with the publishers include mainly the following clauses:

(9) all consortium members have access to all electronic journals of the publishers, provided that each consortium member has at least one current subscription to the publishers' journals;

(10) libraries must keep their payments to each publisher constant for the duration of the agreement;

(11) individual libraries can modify the composition of their collections by substituting ceased titles with other titles of the same publisher and at equal cost.

(12) It is worth mentioning that, since the beginning of 2000, a remarkable expansion of the HEAL-Link consortium is expected, as more libraries have applied to participate in the consortium. These are: 
(13) all seventeen research institution libraries financed by the General Secretariat for Research and Technology;

(14) the Library of the Technical Chamber of Greece; the Library of the University of Cyprus

\section{Conclusions}

(1) The development and operation of the two mechanisms (HEAL-Link and HILLnet) permit (or even push) movement towards a reasonable reconstruction of the national periodical collection through the reduction of duplicated titles. It is obvious that this procedure will start from those journals where:

(a) printed versions currently exist in more than one library;

(b) an electronic version is available via the Internet;

(c) it belongs to one of the contractual publishers;

(d) one subscription to the printed version is kept by one library.

(2) The economic results of the reduction in duplicated journal titles does not lead to saving of money in terms of individual libraries. On the contrary, for those journals, having electronic versions and belonging to one of the contractual publishers, an extra cost of about $10 \%$ to the cost of the corresponding printed version is needed. What is, no doubt, achieved is the breadth of access of all participating libraries to an enormous number of electronic journals, at such high levels that they had never planned or imagined with their limited budgets before their entrance in the consortium.

(3) The complementarities of HILLnet and HEAL-Link are obvious. There is no need for the staff of participating libraries to use HILLnet for those electronic journals to which they have access via HEAL-Link. However, the majority of the electronic journals belonging to the collection of the consortium are available only for a time horizon of two to five years. This happens either because the arrangements with the publishers foresee a five-year perpetual period or because back issues are not (yet) available from the publishers. HILLnet is to be used not only for the back issues, but also for at least $90 \%$ of the journals of the national collection that are not (yet) offered via the electronic collection of HEAL-Link. The same practices of complementary services are also developed by other library consortia all over the world $[10,11]$.

(4) What is foreseen is that, in the near future, the concept and practice of the consortium will be reinforced in Greece. It will be expanded to more types and kinds of information sources (i.e. databases, shared catalogues, common purchases, etc) and extended in the number of participating organisations. Interlibrary lending will gradually be limited. This will happen because more and more journal titles will appear in electronic versions and more and more publishers will form a 'consortium conscience'. 


\section{References}

[1] C. Skourlas, National Documentation Centre: software development for public databases management. In: Online Information 88. Proceedings of the 12th International Online Information Meeting, London, 6-8 December 1988 (Learned Information, Oxford, 1988), pp. 629-640.

[2] F. Tsimpoglou et al., National Documentation Centre, Syllogikos Katalogos Stis Ellenikes Epistemonikes Bibliothekes [Union Catalogue of Periodicals in the Hellenic Scientific Libraries] 5th ed. (National Documentation Centre, Athens, 1998).

[3] Available at: http://iris.ekt.gr:1111/skp/skp_search.login_1

[4] Available at: http://iris.ekt.gr:1111/argos/argos_search.en_login_1

[5] Total Quality Unit of Academic Libraries, University of Ioannina, Statistika Stoixeia Academaikon Bibliothekon 1998-1999, [Statistical Data of Academic Libraries 1998-1999] (University of Ioannina, 1999). See also http://www.lib.uoi.gr/mopab/pubs.htm

[6] Available at: http://iris.ekt.gr:1111/skp/skp_search. login_1

[7] Available at: http://leykada.physics.auth.gr/eabout.htm

[8] Available at: http://www.ntua.gr/library/deliv04.htm (in Greek).

[9] Available at: http://www.library.yale.edu/consortia/

[10] D. Kohl, Resource sharing in a changing Ohio environment (OhioLINK - interlibrary consortium: resource sharing in a changing environment), Library Trends 45(3) (Winter 1997) 435.

[11] W.G. Potter, Recent trends in statewide academic library consortia, Library Trends 45(3) (Winter 1997) 416. 